Proceedings

\title{
Ecological corridors and landscape planning: A study to devel- op a regional network of protected areas in Sardinia (Italy)
}

\author{
Federica Isola ${ }^{1}$, Federica Leone ${ }^{1}$ and Corrado Zoppi ${ }^{1, *}$ \\ 1 Department of Civil and Environmental Engineering and Architecture, University of Cagliari; federi- \\ ca.isola@unica.it (F.I.), federicaleone@unica.it (F.L.) \\ * Correspondence: zoppi@unica.it (C.Z); Tel.: +39070 6755213
}

\begin{abstract}
Ecological corridors (ECs) aim at establishing or maintaining ecological connectivity among habitat patches in terms of migration of wild species, climate change adaptation, and maintenance and restoration of ecological processes. In Sardinia, the Regional Landscape Plan (RLP) defines a spatial taxonomy of the region in relation to landscape components characterized by environmental relevance in order to establish protection levels. Building on previous research works, this study aims at defining and implementing a methodology to identify ECs connecting the Sardinian protected areas and at assessing the relations between ECs and the spatial taxonomy defined by the RLP.
\end{abstract}

Keywords: ecological corridors; regional landscape plan; protected areas

\section{Introduction}

According to IUCN [1], ecological corridors aim at establishing or maintaining ecological connectivity among habitat patches in terms of genetic exchange, migration of wild species [2], climate change adaptation [3], maintenance and restoration of ecological processes [4] and mitigation of undesirable processes [5]. Moreover, connectivity strongly influences ecosystem services (ESs) provision [6]. For example, spatial biotic and abiotic flows affect regulating ESs, such as pollination and seed dispersal [7]. Several authors [8-9] claim that connectivity concerning ESs depends on land cover structure and spatial patterns such as location and physical continuity. Both land cover structure and spatial patterns influence connectivity, which is identified by Taylor et al. as «...the degree to which the landscape facilitates or impedes movement among resource patches» [10] (p. 571).

In Sardinia, an insular region of Italy, RLP approved by the Deliberation of the Sardinian Regional Government no. 36/7 of September 5, 2006, defines a spatial taxonomy of the region on the basis of landscape components characterized by environmental relevance (LCERs) in order to establish protection levels in relation to the value of nature and natural resources.

Building on Cannas' previous research work [11, 12], this study aims at: i. defining and implementing a methodology to identify ECs connecting the Sardinian protected areas; ii. assessing the relations between ECs and the spatial taxonomy defined by the RLP. By means of this methodology, the current RLP zoning code is analyzed in order to detect if, and to what extent, the present planning implementation code can be used to protect and enhance the effectiveness of ECs.

\section{Area of study}

Sardinia is one of the two largest Italian islands, with an area of around $24,000 \mathrm{~km}^{2}$. 
This study analyzes a set of protected areas conceptualized as the nodes of the Sardinian regional ecological network and identified as follows: i. regional parks, identified under the provisions of the Regional Law no. 31/1989; ii. publicly-managed forests, administered by the Regional Agency for Forests; iii. permanent oases of faunal protection, identified under the provisions of the Regional Law no. 23/1998; iv. Ramsar sites, designated under the Ramsar Convention; and, v. Natura 2000 sites, which include Sites of Community Interest (SCI) and Special Areas of Conservation (SAC), established under the provisions of Directive no. 92/42/EEC (the "Habitats Directive"), and Special Protection Areas (SPA), designated by Directive no. 2009/147/EC (the "Birds Directive"). Marine protected areas and national parks are not there because the study only focuses on terrestrial contexts characterized by land cover changes.

\section{Methodology}

This study builds upon a methodology developed by Cannas and applied in previous studies [11,12] where ECs are mapped with reference to the metropolitan city of Cagliari and to the whole Sardinian Regions.

The methodological approach is structured into two main phases. The first phase concerns spatial identification of potential ECs based on the Least-cost path (LCP) and Cost-weighted distance (CWD) analyses. LCP and CWD identify connections between habitat patches that entail minimum resistance to movement and, as a consequence, paths characterized by the highest probability of species flows [13]. In a nutshell, the LCP and CWD analysis finds sequences of least-cost patches which minimize the cost-weighted distance between the nodes of a spatial network in terms of movement.

The first phase is structured into four steps as follows:

1. definition of a habitat suitability map based on findings shown in a report commissioned by the Sardinian regional administration [14], where scores related to habitat suitability are assigned to Sardinian Natura 2000 sites on the basis of the land cover classes identified by the Corine Land Cover (CLC) Taxonomy, and;

2. definition of an ecological integrity map based on Burkhard et al.'s work [15];

3. definition of a resistance map defined on the basis of the inverse of the sum of the habitat suitability and ecological integrity values, according to the approach proposed in a report of the European Environment Agency [16];

4. spatial identification of ECs and definition of a raster map of CWD values, through Linkage Mapper, a GIS tool.

Table 1. Definition and description of variables relating to the LCERs.

\begin{tabular}{cc}
\hline Variable & Description \\
\hline CWD & Cost-weighted distance. \\
SV & Scrub vegetation in dry areas and wetlands \\
WL & Woodlands. \\
GR & Grasslands. \\
CC & Cork and chestnut woods. \\
ST & Specialized and tree crops. \\
AW & Artificial woods. \\
SH & Specialized herbaceous crops, agricultural and forest areas, and un-cultivated areas \\
AL & Altitude \\
\hline
\end{tabular}

In the second phase, the raster map of the CWD values is clustered into ten groups identified by the deciles of its distribution. Patches whose CWD values are lower than the second decile are identified as suitable to be included in an EC. The resulting map is overlaid with the LCERs reported in Table 1. A linear multiple regression model is used in order to assess the relation between patches' suitability to be included in ECs and the spatial taxonomy defined by the RLP. 
The model takes the following form:

$C W D=\beta_{0}+\beta_{1} S V+\beta_{2} W L+\beta_{3} G R+\beta_{4} C C+\beta_{5} S T+\beta_{6} A W+\beta_{7} S H+\beta_{8} A L$ where:

- $\quad$ CWD is the dependent variable;

- $\quad \mathrm{SV}, \mathrm{WL}, \mathrm{GR}, \mathrm{CC}, \mathrm{ST}, \mathrm{AW}, \mathrm{SH}$ are the explanatory variables;

- $\quad \mathrm{AL}$ is a control variable.

\section{Results}

Estimates of the multiple linear regression model are reported in Table 2. The control variable AL shows significant $\mathrm{p}$-values and a positive sign. Therefore, patches characterized by lower CWD or higher connectivity are likely to occur in areas with comparatively lower altitude, such as flat areas, as expected.

The explanatory variables related to the LCERs are expressed as percentages of the patch areas. The estimates of the marginal effects on CWD are significant at $6.6 \%$, with the exception of SV, which is only significant at 10.8 percent.

The results of the regression show that being identified as a LCER has a positive impact on the suitability of a patch to be part of an EC, since the percentage increase in each LCER is correlated with a decrease in CWD, with the exception of specialized and tree crops (ST), whose coefficient is positive and indicates that a 1 percent increase in ST at the regional level entails an average increase of about 7.7 meters in the average CWD of the ECs.

Table 2. Regression results.

\begin{tabular}{cccccc}
\hline Variable & Coefficient & $\begin{array}{c}\text { Standard } \\
\text { Deviation }\end{array}$ & t-statistic & p-value & Mean \\
\hline SV & -2.77172 & $26,775.40$ & -1.60534 & 0.108428 & $16,962.44$ \\
WL & -7.20867 & $29,513.47$ & -4.16805 & 0.000031 & $18,038.76$ \\
GR & -5.80510 & $27,314.39$ & -3.35834 & 0.000785 & $18,879.67$ \\
CC & -6.91227 & $12,865.24$ & -3.49271 & 0.000479 & $3,190.58$ \\
ST & 7.70003 & $11,326.36$ & 3.69729 & 0.000218 & $3,107.70$ \\
AW & -5.33205 & $16,500.74$ & -2.85482 & 0.004309 & $4,721.13$ \\
SH & -3.16692 & $31,984.68$ & -1.84476 & 0.065081 & $23,207.82$ \\
AL & 1.45191 & 275.76 & 22.37541 & 0.000000 & 365.36 \\
\hline
\end{tabular}

As regards the remaining LCERs, wooded areas (WL) and cork and fruit chestnut woods (CC) are the most suitable to enhance the effectiveness of the ECs, with coefficients equal to 7.2 and 6.9 respectively, that implies an average ECs' CWD decrease of 7.2 meters and 6.9 meters related to a 1\% increase at the regional level. Grasslands (GR) and artificial woods (AW) show positive and slightly lower impacts, since their coefficients are equal to 5.81 and 5.33 respectively. Finally, the marginal effects of the variables related to scrub vegetation in dry areas and wetlands (SV, coefficient equal to 2.77 ), and to specialized herbaceous crops, agricultural and forest areas, and uncultivated areas $(\mathrm{SH}$, coefficient equal to 3.16), are decidedly lower.

\section{Conclusions}

The estimates of model (1) help to assess whether, and to what extent, the current zoning rules of the RLP are suitable to implement an effective spatial system of ECs.

The transition of land uses from agriculture to forestry is associated to a decrease in CWD. For this to take place, public financial support is definitely needed to compensate the income loss of farmers. This is likely to occur, in terms of financial feasibility, as regards areas classed as SH (specialized herbaceous crops, agricultural and forest areas, and un-cultivated areas) and, to a greater extent, with reference to ST areas (specialized and tree crops), whereas transitions concerning agricultural intensive production, characterized by the highest rents, are unlikely, due to the often unaffordable public financial effort needed thereof. 
In conclusion, spatial policies aimed at strengthening the effectiveness of regional 1 networks of the natural protected areas through the protection and enhancement of ECs must be studied, defined and implemented on the basis of habitat quality, ecological integrity and health of ecosystems, with particular attention to land use conditions and transition opportunities.

Author Contributions: Federica Isola (F.I.), Federica Leone (F.L.), and Corrado Zoppi (C.Z.) collaboratively designed this study. Individual contributions are as follows: F.I. wrote Section 1 and 2; F.L. wrote Section 3 and 5; C.Z. wrote Section 4.

Funding: This research received no external funding.

Acknowledgments: The study was implemented within the Research Program "Paesaggi rurali della Sardegna: pianificazione di infrastrutture verdi e blu e di reti territoriali complesse" [Rural landscapes of Sardinia: Planning policies for green and blue infrastructure and spatial complex networks], funded by the Autonomous Region of Sardinia for the period 2019-2021

Conflicts of Interest: The authors declare no conflict of interest.

\section{References}

1. Hilty, J.; Worboys, G.L.; Keeley, A.; Woodley, S.; Lausche, B.; Locke, H.; Carr, M.; Pulsford, I.; Pittock, J.; White, J.W.; Theobald, D.M.; Levine, J.; Reuling, M.; Watson, J.E.M.; Ament, R.; Tabor, G.M. Guidelines for Conserving Connectivity through Ecological Networks and Corridors. Best Practice Protected Area Guidelines Series no. 30; IUCN: Gland, Switzerland, 2020.

2. Menxiu, T.; Lin, Z.; Li, J.; Zöckler, C.; Clark, N.A. The critical importance of the Rudong mudflats, Jiangsu Province, China in the annual cycle of the spoon-billed sandpiper Calidris pygmeus. Wader Study Group Bulletin 2012, 119(3), 74-77.

3. Keeley, A.T.H; Ackerly, D.D.; Cameron, D.R.; Heller, N.E.; Huber, P.R.; Schloss, C.A.; Thorne, J.H.; Merenlender, A.M. New concepts, models, and assessments of climate-wise connectivity. Environ. Res. Lett. 2018, 13, 073002 (18 pp.).

4. Doyle, M.W.; Stanley, E.H.; Luebke, M.A.; Harbor, J.M. Dam removal: Physical, biological, and societal considerations. In Building Partnerships, Proceedings of the 2000 Joint Conference on Water Resources Engineering and Water Resources Planning and Management; Minneapolis, MN, 2000; pp. 1-10.

5. Ladonina, N.N.; Cherniakhovsky, D.A.; Makarov, I.B.; Basevich, V.F. Managing agricultural resources for biodiversity conservation: Case study of Russia and CIS countries. Environment Liaison Center International, 2001.

6. Mitchell, M.G.E.; Bennett, E.M.; Gonzalez, A. Linking landscape connectivity and ecosystem service provision: Current knowledge and research gaps. Ecosystems 2013, 16(5), 894-908.

7. Kremen, C.; Williams, N.M.; Aizen, M.A.; Gemmill-Herren, B.; LeBuhn, G.; Minckley, R.; Packer, L.; Potts, S.G.; Roulston, T.; Steffan- Dewenter, I.; Vazquez, D.P.; Winfree, R.; Adams, L.; Crone, E.E.; Greenleaf, S.S.; Keitt, T.H.; Klein, A-M.; Regetz, J.; Ricketts, T.H. Pollination and other ecosystem services produced by mobile organisms: a conceptual framework for the effects of land-use change. Ecol. Lett. 2007, 10(4), 299-314.

8. D'Ambrogi, S.; Gori, M.; Guccione, M.; Nazzini, L. Implementazione della connettività ecologica sul territorio: Il Monitoraggio ISPRA 2014 [The implementation of spatial ecological connectivity: The 2014 Monitoring of ISPRA]. Reticula 2015, 9, 1-7.

9. Mitchell, M.G.E.; Bennett, E.M.; Gonzalez, A. Linking landscape connectivity and ecosystem service provision: Current knowledge and research gaps. Ecosystems 2013, 16(5), 894-908.

10. Taylor, P.; Fahrig, L.; Henein, K.; Merriam, G. Connectivity is a vital element of landscape structure. Oikos 1993, 68, 571-573.

11. Cannas, I.; Zoppi, C. Ecosystem services and the Natura 2000 Network: A study concerning a green infrastructure based on ecological corridors in the metropolitan city of Cagliari. In 17th International Conference on Computational Science and Its Applications (ICCSA 2017), Lecture Notes in Computer Sciences Series; Gervasi, O., Murgante, B., Misra, S., Borruso, G., Torre, C., Rocha, A.M.A.C., Taniar, D., Apduhan, B.O., Stankova, E., Cuzzocrea, A., Eds.; Springer: Cham, Switzerland, 2017; Volume 10409, pp. 379-400.

12. Cannas, I.; Lai, S.; Leone, F.; Zoppi, C. Green infrastructure and ecological corridors: A regional study concerning Sardinia. Sustainability 2018, 10(4), 1265 (21 pp.).

13. Balbi, M.; Petit, E.J.; Croci, S.; Nabucet, J.; Georges, R.; Madec, L.; Ernoult, A. Title: Ecological relevance of least cost path analysis: An easy implementation method for landscape urban planning. J. Environ. Manage. 2019, 244, pp. 61-68.

14. AGRISTUDIO; CRITERIA; TEMI. Realizzazione del Sistema di Monitoraggio dello Stato di Conservazione degli Habitat e delle Specie di Interesse Comunitario della Regione Autonoma della Sardegna. Relazione Generale, Allegato 1b: Carta dell'Idoneità Faunistica [Implementation of the Monitoring System Concerning the Conservation Status of Habitats and Species of Community Interest of the Autonomous Region of Sardinia. General Report, Attachment 1b: Habitat Suitability Map]; MIMEO. Unpublished work, 2011.

15. Burkhard, B.; Kroll, F.; Müller, F.; Windhorst, W. Landscapes' Capacities to provide ecosystem services - a concept for land-cover based assessments. Landscape Online 2009, 15, pp. 1-22.

16. EEA (European Environment Agency). Spatial Analysis of Green Infrastructure in Europe, EEA Technical Report no. 2/2014; Publications Office of the European Union: , Luxembourg, 2014. 